\title{
Local In Vivo Measures of Muscle Lipid and Oxygen Consumption Change in Response to Combined Vitamin D Repletion and Aerobic Training in Older Adults
}

\author{
D. Travis Thomas ${ }^{1, *(\mathbb{D})}$, David M. Schnell ${ }^{2}$, Maja Redzic ${ }^{2}$, Mingjun Zhao $^{3}$, Hideat Abraha ${ }^{2}$, \\ Danielle Jones ${ }^{2}$, Howard Brim ${ }^{3}$ and Guoqiang $\mathrm{Yu}^{3}$ \\ 1 College of Health Sciences, University of Kentucky, Lexington, KY 40536, USA \\ 2 Department of Pharmacology \& Nutritional Sciences, University of Kentucky, Lexington, KY 40536, USA; \\ dave.schnell@uky.edu (D.M.S.); mre226@g.uky.edu (M.R.); hideat.abraha@gmail.com (H.A.); \\ Danielle.Jones@uky.edu (D.J.) \\ 3 Department of Biomedical Engineering, University of Kentucky, Lexington, KY 40536, USA; \\ mingjun.zhao@uky.edu (M.Z.); howard.brim@uky.edu (H.B.); gyu2@uky.edu (G.Y.) \\ * Correspondence: dth225@uky.edu or david.t.thomas@uky.edu; Tel.: +1-(859)-218-0863
}

Received: 29 March 2019; Accepted: 22 April 2019; Published: 25 April 2019

check for updates

\begin{abstract}
Intramyocellular (IMCL), extramyocellular lipid (EMCL), and vitamin D deficiency are associated with muscle metabolic dysfunction. This study compared the change in [IMCL]:[EMCL] following the combined treatment of vitamin D and aerobic training (DAT) compared with vitamin D (D), aerobic training (AT), and control (CTL). Male and female subjects aged 60-80 years with a BMI ranging from 18.5-34.9 and vitamin $\mathrm{D}$ status of $\leq 32 \mathrm{ng} / \mathrm{mL}(25(\mathrm{OH}) \mathrm{D})$ were recruited to randomized, prospective clinical trial double-blinded for supplement with a $2 \times 2$ factorial design. Cholecalciferol $\left(\right.$ Vitamin $\left.D_{3}\right)(10,000$ IU $\times 5$ days/week) or placebo was provided for 13 weeks and treadmill aerobic training during week 13. Gastrocnemius IMCL and EMCL were measured with magnetic resonance spectroscopy (MRS) and MRI. Hybrid near-infrared diffuse correlation spectroscopy measured hemodynamics. Group differences in IMCL were observed when controlling for baseline IMCL $(p=0.049)$. DAT was the only group to reduce IMCL from baseline, while a mean increase was observed in all other groups combined $(p=0.008)$. IMCL reduction and the corresponding increase in $\mathrm{rVO}_{2}$ at study end ( $p=0.011$ ) were unique to DAT. Vitamin D, when combined with exercise, may potentiate the metabolic benefits of exercise by reducing IMCL and increasing tissue-level $\mathrm{VO}_{2}$ in healthy, older adults.
\end{abstract}

Keywords: skeletal muscle; IMCL; sarcopenia; metabolic function; vitamin D

\section{Introduction}

Skeletal muscle metabolic dysfunction is the cornerstone of pathogenesis for most age-related co-morbidities. Understanding and combating muscle metabolic dysfunction in older adults has the potential to limit loss of strength and physical function [1], and improve quality of life. Vitamin D supplementation has been widely studied as a potential strategy to maintain physical function in aging [2-4] and vitamin D status has been positively associated with improving various metabolic outcomes [5-8]. While vitamin D insufficiency is estimated to contribute to $\$ 40$ to $\$ 60$ billion of economic burden annually [9], the mechanisms whereby vitamin D elicits physiological outcomes is not fully established in many tissues, and vitamin D interventions do not always result in improvements in physical function $[10,11]$. A better understanding of the effects of vitamin D deficiency and repletion, 
in relation to muscle metabolic function in aging is needed to further elucidate the metabolic benefits of vitamin $\mathrm{D}$ repletion in aging.

To date, exercise is the best known non-pharmacologic strategy to improve and maintain muscle function; however, response to exercise is diminished in the elderly, and the variability of response is increased. Several lines of current research indicate that vitamin D status may exacerbate this variability and skeletal muscle trophicity in general [12]. For example, low serum 25-hydroxyvitamin $\mathrm{D}(25(\mathrm{OH}) \mathrm{D})$ is associated with increased muscle degeneration and fatty substitution [13], decreased muscle fiber size [14], and reduced muscle protein fractional synthetic rate [15]. Vitamin D deficiency has also been implicated in metabolic dysfunction associated with skeletal muscle including insulin resistance (IR) [16], inflammation [17], and extramyocellular lipid (EMCL) accrual [13,18]. Conversely, meta-analysis has shown that vitamin D supplementation increases muscle strength, with greatest improvements in those who have the most severe deficiency [19].

Recent reports suggest that vitamin D coupled with exercise has added positive effects on muscle mitochondrial function [6,7]. In addition, vitamin D receptor (VDR) expression in skeletal muscle is increased by both exercise [20] and vitamin D supplementation and has been associated with muscle regeneration and repair [14,21,22], suggesting an additive effect when exercise is combined with vitamin D repletion. Moreover, a synergistic interaction between exercise and vitamin $\mathrm{D}$ has been suggested [20]. Research in rodents has shown that exercise may improve skeletal muscle sensitivity to vitamin D by increasing the expression of CYP27B1 [20] and that vitamin D supports whole body $\beta$-oxidation [23], further supporting the connection between vitamin D and exercise [24]. Given these findings, it is conceivable that vitamin D deficiency coupled with aging and sedentary behavior [25] may contribute to muscle metabolic dysfunction. Furthermore, the age-associated decline in muscle metabolic function may be preceded by changes in intramuscular lipid [26]. Low levels of physical activity and vitamin D insufficiency appear to independently influence intramuscular lipid and may both contribute to impairments in muscle metabolic function $[27,28]$. This is important because derangements in muscle lipid metabolism are associated with mitochondrial dysfunction, muscle lipid stagnation, inefficient fat oxidation, and insulin signaling impairments [29]. Vitamin D has been inversely associated with EMCL $[13,18]$, and to our knowledge, we were the first to report a positive linear relationship between vitamin D status and intramyocellular lipid (IMCL) in healthy, aged adults [27]. IMCL accumulation is linked to dysregulation of glucose homeostasis and IR in sedentary and aged individuals [30,31]. However, small amounts of moderate intensity aerobic exercise has been shown to increase oxidative capacity and overall fitness while expanding IMCL content [32,33]. Moreover, our IMCL findings [27] in a healthy, aged cohort were independent of body mass and daily physical activity, providing support to the notion of vitamin D dependent IMCL accretion.

Coupled with these findings, along with evidence that short-term aerobic training (AT) promotes an increase in IMCL in aged adults [34], we hypothesized that vitamin D repletion promotes accumulation of IMCL; this IMCL is in turn more readily oxidized with the addition of AT. In order to test this hypothesis, the primary outcome of this study was to identify changes in muscle lipid ([IMCL]/[EMCL] ratio) in older adults following the combined treatment of vitamin D repletion and AT compared to vitamin D repletion alone, AT alone, and control conditions using magnetic resonance imaging (MRI) and spectroscopy (MRS). We also aimed to quantify the local muscle oxygen consumption rate $\left(\mathrm{VO}_{2}\right)$ using near-infrared and diffuse correlation spectroscopies (NIRS/DCS) to evaluate how local muscle tissue metabolism is related to lipid partitioning between each treatment group.

\section{Materials and Methods}

Normal weight to class I obese $\left(B M I=18.5\right.$ to $\left.34.9 \mathrm{~kg} / \mathrm{m}^{2}\right)$ subjects between the ages of 60 and 80 years of age were recruited. Subjects were not eligible if receiving treatment for vitamin $\mathrm{D}$ deficiency or if they had a recent history of vitamin $\mathrm{D}$ supplementation. Additional exclusion criteria included history of myopathy, neurologic disorders, disk disease, peripheral neuropathies, lower extremity surgery, or leg injury in the past 3 months. Final enrollment decisions were contingent 
upon serum $25(\mathrm{OH}) \mathrm{D}$ concentrations $(\leq 32 \mathrm{ng} / \mathrm{mL})$ and asymptomatic electrocardiogram findings from a graded treadmill exercise test (GXT). The study was approved by the university Institutional Review Board, and all eligible subjects gave informed written consent prior to engaging in baseline measures. All institutional and governmental regulations concerning the use of human volunteers were followed during this research. See Figure 1 and Table 1 for screening and accrual details and baseline characteristics. There were no adverse events associated with participating in this study.

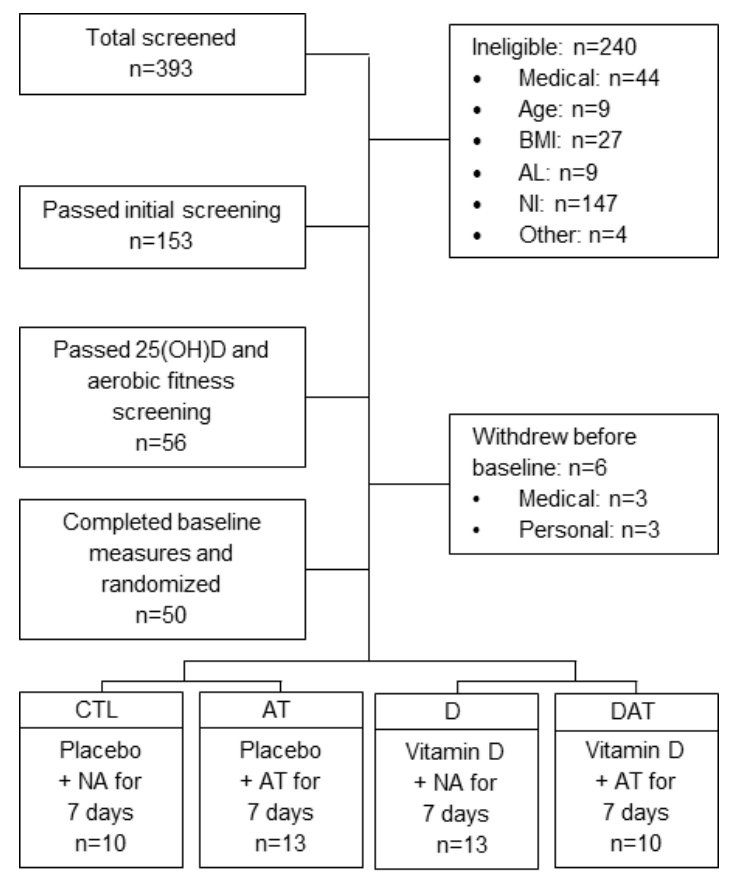

Figure 1. Recruitment for a randomized placebo-controlled clinical trial, in which aged adults completed seven consecutive days of aerobic training on a treadmill or continued usual activities (normal activity during the 13th week of vitamin D supplementation or place)bo. Serum $25(\mathrm{OH}) \mathrm{D}$, serum 25-hydroxyvitamin D; AL, activity level; AT, aerobic training; CTL, control; D, vitamin D; DAT, vitamin D + aerobic training; NI, not interested; NA, normal activity.

Table 1. Baseline characteristics of the 46 subjects who completed 13 weeks of supplementation with vitamin D or placebo with the 13th week consisting of AT or usual physical activities.

\begin{tabular}{|c|c|c|c|c|c|}
\hline Category & Measurement & CTL & AT & D & DAT \\
\hline \multirow{5}{*}{ Demographics } & $N$ (Male/Female) & $10(3 / 7)$ & $13(7 / 6)$ & $13(6 / 7)$ & $10(5 / 5)$ \\
\hline & Age, years & $67.5 \pm 2.1$ & $68.6 \pm 1.3$ & $65.9 \pm 1.6$ & $67.9 \pm 1.9$ \\
\hline & White & 9 & 13 & 12 & 9 \\
\hline & Asian & 1 & 0 & 1 & 0 \\
\hline & African American & 0 & 0 & 0 & 1 \\
\hline \multirow{3}{*}{$\begin{array}{l}\text { Anthropometric } \\
\text { Measurements }\end{array}$} & Height, $\mathrm{cm}$ & $167 \pm 3.0$ & $170 \pm 2.0$ & $168 \pm 3.0$ & $169 \pm 3.0$ \\
\hline & Weight, kg & $75.1 \pm 3.8$ & $72.2 \pm 3.4$ & $76.1 \pm 4.1$ & $74.6 \pm 5.0$ \\
\hline & $\mathrm{BMI}, \mathrm{kg} / \mathrm{m}$ & $27.0 \pm 1.2$ & $24.7 \pm 0.8$ & $26.6 \pm 0.9$ & $26.2 \pm 1.5$ \\
\hline \multirow{3}{*}{$\begin{array}{c}\text { Serum } \\
\text { Measurements }\end{array}$} & $25(\mathrm{OH}) \mathrm{D}, \mathrm{ng} / \mathrm{mL}$ & $24.8 \pm 2.1$ & $25.2 \pm 1.4$ & $26.6 \pm 1.2$ & $27.1 \pm 1.6$ \\
\hline & VDBP, $\mu \mathrm{g} / \mathrm{mL}$ & $110 \pm 5$ & $114 \pm 3$ & $111 \pm 4$ & $115 \pm 5$ \\
\hline & $\mathrm{iPTH}, \mathrm{pg} / \mathrm{mL}$ & $36.8 \pm 3.6^{\mathrm{AB}}$ & $32.4 \pm 2.6^{B}$ & $53.1 \pm 5.5^{C}$ & $47.6 \pm 5.0^{\mathrm{BC}}$ \\
\hline \multirow{6}{*}{$\begin{array}{l}\text { Physiological } \\
\text { Measurements }\end{array}$} & $\mathrm{VO}_{2} \max , \mathrm{mL} /(\mathrm{kg} \min )$ & $25.8 \pm 1.8$ & $28.0 \pm 2.9$ & $28.4 \pm 2.1$ & $27.0 \pm 2.8$ \\
\hline & Light $\mathrm{PA}, \mathrm{min} / \mathrm{d}$ & $878 \pm 67$ & $839 \pm 53$ & $956 \pm 68$ & $806 \pm 32$ \\
\hline & Moderate PA, min/d & $63.2 \pm 11.7$ & $52.0 \pm 5.9$ & $59.4 \pm 7.7$ & $69.6 \pm 11.1$ \\
\hline & Vigorous PA, min/d & $0.28 \pm 0.14$ & $0.21 \pm 0.11$ & $0.69 \pm 0.69$ & $1.15 \pm 0.82$ \\
\hline & $\mathrm{MVC}, N \mathrm{~m}$ & $128 \pm 7.6$ & $139 \pm 10.9$ & $149 \pm 8.5$ & $140 \pm 10.7$ \\
\hline & Energy Intake, kcal/d & $1741 \pm 156$ & $2045 \pm 325$ & $1457 \pm 119$ & $1789 \pm 241$ \\
\hline
\end{tabular}

All values are mean \pm SEM. Serum $25(\mathrm{OH}) \mathrm{D}$, serum 25-hydroxyvitamin $\mathrm{D} ; \mathrm{AT}$, aerobic training only; CTL, control; $\mathrm{D}$, vitamin D only; DAT, vitamin D + aerobic training; MVC, maximum voluntary contraction; $\mathrm{PTH}$, intact parathyroid hormone, $\mathrm{PA}$, physical activity; VDBP, vitamin $\mathrm{D}$ binding protein; $\mathrm{VO}_{2}$ max, maximal aerobic capacity. Values not sharing a letter are significantly different ( $p<0.05$, ANOVA, Fishers LSD). 


\subsection{Study Design}

This was a randomized, prospective clinical trial double-blinded for supplement with a $2 \times 2$ factorial design (Clinical Trial Registry: NCT02221596). This 13-week trial was designed to compare the magnitude of change in the [IMCL]/[EMCL] ratio (primary outcome) and local muscle blood flow and oxygen consumption rate (secondary outcomes) following treatment with vitamin D repletion alone (D), aerobic training alone (AT), both vitamin D repletion and aerobic training (DAT), and control conditions (CTL).

\subsection{General Clinical Procedures}

Anthropometric assessments were completed at weeks 0 and 13 as indicated in the subject timeline (Figure 2). Blood draws were performed to measure serum ionized calcium (iCa) and intact parathyroid hormone (iPTH), vitamin D binding protein (VDBP), and 12-h fasting insulin during weeks 0,6 , and 13 . Serum $25(\mathrm{OH}) \mathrm{D}$, measured via LC-MS, was obtained during screening and was used as baseline values. VDBP, iPTH, and iCa variables were measured via ELISA to monitor the safety of our repletion strategy and provide a comprehensive systemic assessment of the response to our vitamin D supplementation intervention. Serum insulin was measured at baseline and endpoint to calculate HOMA-IR and to subsequently assess insulin secretion and insulin sensitivity. The coefficient of variation was $<10 \%$ for all blood analyses. MRI and MRS measures of gastrocnemius EMCL and IMCL were collected on the same testing day as anthropometrics measures (weeks 0 and 13). Following MRI, we collected NIRS/DCS optical data in the same region of the gastrocnemius. We integrated NIRS/DCS technology with our gastrocnemius plantar flexion fatigue protocol (described below) to assess changes in local skeletal muscle metabolic function from baseline to endpoint. Following baseline testing, all subjects were randomized to either DAT, D, AT or CTL treatment.

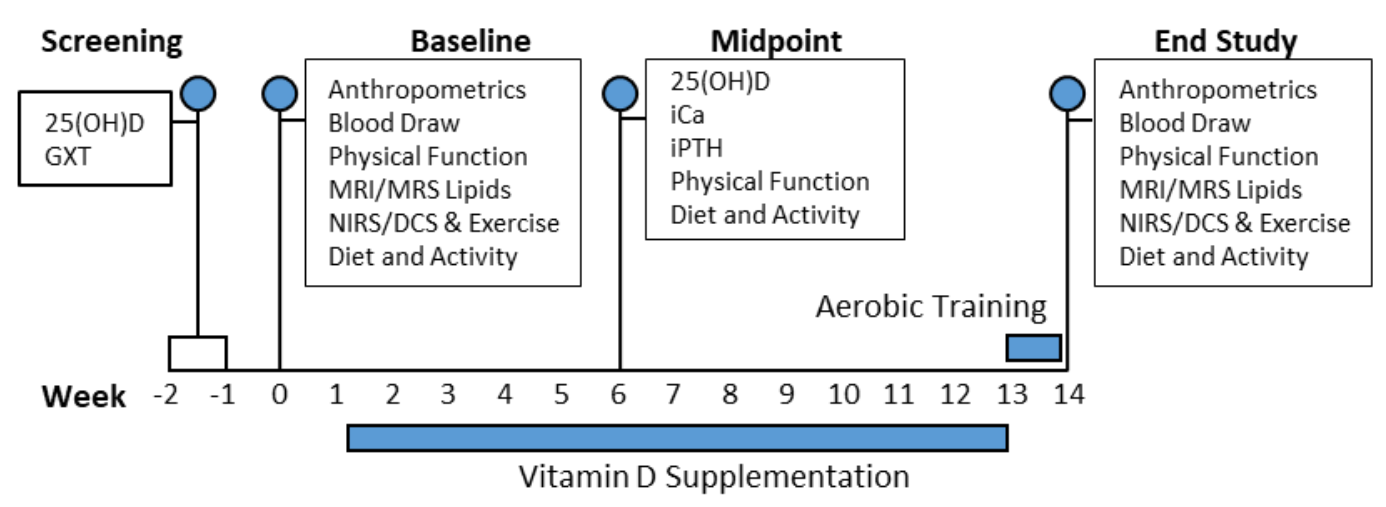

Figure 2. Schematic representation of the subject timeline. Serum $25(\mathrm{OH}) \mathrm{D}$, serum 25-hydroxyvitamin D; GXT, graded treadmill exercise test; iCa, serum ionized calcium; iPTH, serum intact parathyroid hormone; MRI/MRS, magnetic resonance imaging/spectroscopy; NIRS/DCS, near-infrared spectroscopy/diffuse correlation spectroscopy.

Subjects were instructed to maintain their usual dietary patterns throughout the duration of the study and energy intake was assessed via 24-hr dietary recall. Dietary recalls at each study time point consisted of 3 randomly selected, non-consecutive days including 1 weekend and 2 week days for a total of 9 recalls. Energy content was determined using Nutrition Data System for Research (NDS-R, Version 2017, University of Minnesota, Minneapolis, MN, USA).

Subjects wore an ActiGraph (MTI, Inc. Fort Walton Beach, FL, USA) to measure average daily activity over a 7-day data collection period during each time point. A complete description of the ActiGraph and its technical reliability have been published elsewhere [35,36]. The data collection interval was set at one minute with a minimum wear of $12 \mathrm{~h}$ required to constitute a valid day. 
During screening, all subjects completed a graded treadmill exercise test (GXT) using a VMAX Encore metabolic cart (Vyaire, Yorba Linda, $\mathrm{CA}$, USA) with $\mathrm{O}_{2}$ measures to derive systemic $\mathrm{VO}_{2 \max }$. This multi-staged treadmill GXT was performed using progressive 2-min workload stages. The initial speed of the treadmill was set based on the participant's reported fitness level prior to the start of the test in an attempt to limit the test time to between 8-12 $\mathrm{min}$ in accordance with the American College of Sports Medicine (ACSM) Guidelines for Exercise Testing and Prescription [37].

\subsection{Vitamin D and Placebo Supplementation Protocol}

Vitamin D repletion occurred in a double-blinded randomized placebo-controlled fashion. Vitamin D repletion goals were set to increases $25(\mathrm{OH}) \mathrm{D}$ from $20-32 \mathrm{ng} / \mathrm{mL}$ to greater than $40 \mathrm{ng} / \mathrm{mL}$. We chose this repletion target because it is a commonly referenced concentration hypothesized to maintain extra-skeletal health [38]. Our repletion strategy was designed to promote a 25(OH)D steady state [39], correct vitamin D insufficiency, and was similar with previous dosing strategy that reported changes in muscle metabolic function [6,39]. The study coordinator was blinded to supplement assignment and provided supplement allocations every 2 weeks. The study coordinator instructed subjects to self-administer 2 gelcaps at the same time by mouth daily during the morning hours (10,000 IU/day $\times 5$ days/wk Cholecalciferol (vitamin $\mathrm{D}_{3}$ ) or placebo). Supplement compliance was determined by subject self-reports and pill counts. Any unused gelcaps were returned to study personnel at week 6 and at endpoint.

BioTech Pharmacal, Inc. supplied all vitamin D and placebo gelcaps and has supplied vitamin $\mathrm{D}$ and placebo for previously published clinical trials. The company follows FDA GMP standards for quality assurance for physical attributes, capsule content, and purity. Vitamin D and placebo gelcaps were identical in size, weight and appearance. Vitamin D gelcaps were encapsulated in a clear gelatin two-piece capsule (size 4), filled with white powder and the active ingredients, vitamin $\mathrm{D}_{3}$ (Cholecalciferol) $5000 \mathrm{IU}$ with microcrystalline cellulose, and gelatin (inactive ingredients). Placebo capsules were identical and filled with microcrystalline cellulose, gelatin (inactive ingredients) and no active vitamin D. Both products met USP specifications for capsule weight variation and met USP and Prop. 65 guidelines for heavy metals.

\subsection{Aerobic Training Protocol}

Our exercise intervention was based on an acute 7-day intervention consisting of daily aerobic exercise [34] in older adults that resulted in intramuscular lipid repartitioning. For seven consecutive days during week 13, subjects randomized to AT or DAT performed $60 \mathrm{~min}$ of treadmill exercise at an intensity up to $60-65 \%$ of their maximum heart rate (approximately $55-65 \%$ of their maximal baseline aerobic capacity). During exercise sessions, subjects wore heart rate monitors (Polar T31; Polar Electro, Kempele, Finland) to monitor target heart rate.

\subsection{Muscle Lipid Assessment}

Lipid was quantified using single voxel, hydrogen magnetic resonance spectroscopy (MRS) to distinguish IMCL from EMCL. Subjects were positioned in supine orientation with their lower leg in the transmit/receive knee coil in a fixed dorsiflexed position parallel to the main magnetic field, a 3.0T TIM TRIO scanner (Siemens, Erlangen, Germany). Spectral fitting was carried out using the software package LcModel (Stephen Provencher Inc., Oakville, ON, Canada). Then, 1H-MRS was used to quantify IMCL (TR/TE $=2000 / 30 \mathrm{~ms}$ ). EMCL was quantified using T1 scans with and without fat saturation and an automated segmentation program, FMRIB Software Library version 5.0 (FMRIB, Oxford, UK). Sets of T1-weighted images (TR/TE $=650 / 22 \mathrm{~ms}$ ) for high-resolution anatomy were used to assess EMCL. Medial and lateral heads of the gastrocnemius were quantified and combined to assess total EMCL content. EMCL was reported as percent of gastrocnemius volume (\%gast), and IMCL was reported as the ratio of IMCL:water spectral abundance $\times 1000(\mathrm{AU})$. 


\subsection{Fatigue Gastrocnemius Plantar Flexion Protocol Coupled with Hybrid Diffuse Optical Spectroscopy (NIRS/DCS)}

At baseline and endpoint, subjects were seated at $70^{\circ}$ in a semi-recumbent position on a dynamometer (BTE Primus RS, Hanover, MD, USA) with the calf exposed for easy placement of optical spectroscopy probes. Following a warm up, a minimum of five maximal voluntary isometric plantar contractions (MVC) were completed to determine maximum torque generation. MVC attempts were repeated until coefficient of variance fell below $10 \%$, and the highest concentric plantar-flexion peak-torque value was recorded as the MVC. A 3-min rest was provided prior to the start of fatigue exercise to allow for pre-fatigue NIRS/DCS measures. Following MVC determination, an optical probe connected to the hybrid diffuse optical instrument (NIRS/DCS) combining a commercial NIRS oximeter (Imagent, ISS Inc., Champaign, IL, USA) and a custom built DCS flowmeter was placed over the right calf (medial gastrocnemius) and attached to the belly of the muscle. Gastrocnemius hemodynamics, including blood flow $(\mathrm{BF})$, blood oxygen saturation $\left(\mathrm{StO}_{2}\right)$, and oxygen consumption rate $\left(\mathrm{VO}_{2}\right)$, were continuously measured from $3 \mathrm{~min}$ prior to the start of the fatigue exercise to $15 \mathrm{~min}$ after its completion [40,41]. Subjects were asked to complete 75 repetitions of isotonic concentric plantar-flexion contractions at maximal voluntary angular velocity with torque set to $35 \%$ of MVC. Optical hemodynamic data were collected at the end of every concentric phase plantar-flexion $(0.5 \mathrm{~s}$ measurement periods) during exercise to reduce motion artifact [40,42]. Optical measurements were normalized to a resting optical baseline before baseline and endpoint measurements; relative $\mathrm{BF}(\mathrm{rBF})$ and relative $\mathrm{VO}_{2}\left(\mathrm{rVO}_{2}\right)$ were then calculated by methods described elsewhere [41]. Change in $\mathrm{StO}_{2}$ $\left(\Delta \mathrm{StO}_{2}\right)$ was calculated as the increase in $\mathrm{StO}_{2}$ at all measurement times from resting $\mathrm{StO}_{2}$ to minimize the influence of individual variation in resting $\mathrm{StO}_{2}$ and to enhance the $\mathrm{StO}_{2}$ response induced by the fatigue exercise. Post-fatigue exercise recovery in $\mathrm{rVO}_{2}$ was characterized by the recovery half-time (T50), a time interval from the end of exercise to the time that they reached a half-maximal value.

\subsection{Statistical Methods}

Sample size was estimated based on the expectation that AT groups would have a lower [IMCL]/[EMCL] ratio, with the lowest ratio in DAT. Previous research measuring EMCL and IMCL in vivo reported changes of $-5.8 \pm 3.4 \%$ gast and $0.5 \pm 0.2 \mathrm{AU}$, respectively, following a 7 -day diet and exercise intervention [34]. With the assumption that vitamin D combined with AT change EMCL and the [IMCL]/[EMCL] ratio changes similarly and that the change is smallest in the group without vitamin D or AT, a two-way analysis of variance (repeated measures (RMANOVA)) was estimated to have at least $80 \%$ power to detect the main effects of vitamin D and AT (sample size is 11 per group, $n=44)$. IMCL and EMCL comparisons between groups were also assessed using two-way RMANOVA to align with our primary outcome analysis. We suspected that small differences in baseline IMCL could contribute directly to the determination of the size of the differences at endpoint. For this reason, baseline IMCL values were included as a covariate and were included in secondary analysis of intervention effects using Analysis of Covariance (ANCOVA).

RMANOVA was also used to compare NIRS/DCS outcomes in all study groups for secondary outcomes. Fisher's least significant difference (LSD) was used for post hoc analysis to identify specific group differences when main effect ANOVA $p<0.05$. Exploratory analysis included examining correlation coefficients using Pearson's $r$ between $25(\mathrm{OH}) \mathrm{D}$ and iPTH, $\Delta 25(\mathrm{OH}) \mathrm{D}$ and $\triangle \mathrm{IMCL}$, and other physiological variables. Within group comparisons of muscle lipid depots were exploratory and assessed using paired t-test between baseline and endpoint. All analyses were performed using SPSS ${ }^{\circledR}$ statistical software version 22.0 (IBM Corporation, Armonk, NY, USA) and significance was defined as $p<0.05$. Values presented as mean \pm SEM. 


\section{Results}

\subsection{Muscle Lipid}

For our primary outcome of examining differences in the [IMCL]/[EMCL] ratio, there were no significant effects in response to treatment (supplement, $p=0.121$; treadmill, $p=0.178$; interaction, $p=0.915)$ and no time or group main effects $(p=0.29)$. When analyzed separately, there were no significant differences in IMCL or EMCL by time and/or supplement or treadmill training (Table 2). However, a significant difference in mean IMCL change $\left(p=0.049 ; \eta^{2}=0.301\right)$ between intervention groups was observed when controlling for baseline IMCL variability using ANCOVA. A trend in DAT IMCL reduction was observed (Table 2$)$, while a mean increase $(1.11 \pm 0.32 \mathrm{AU})$ was observed in all other groups combined $(p=0.008)$. There were no sex differences in the [IMCL]/[EMCL] ratio, IMCL, or EMCL by time and/or by group.

Table 2. Gastrocnemius muscle lipid before and after 13 weeks of supplementation with vitamin D or placebo with the 13th week consisting of AT or usual physical activities.

\begin{tabular}{cccccc}
\hline Value & Time point & CTL & AT & D & DAT \\
\hline IMCL & Baseline & $4.84 \pm 0.94$ & $3.93 \pm 0.67$ & $3.93 \pm 0.61$ & $4.27 \pm 0.93$ \\
& Endpoint & $5.01 \pm 0.72$ & $4.10 \pm 0.92$ & $3.95 \pm 0.65$ & $2.26 \pm 0.61$ \\
& Change & $0.16 \pm 0.54$ & $0.17 \pm 0.68$ & $0.02 \pm 0.47$ & $-2.02 \pm 0.78 *$ \\
EMCL & Baseline & $27.3 \pm 2.4$ & $26.0 \pm 1.1$ & $28.0 \pm 1.8$ & $25.8 \pm 1.4$ \\
& Endpoint & $25.5 \pm 2.0$ & $25.7 \pm 1.4$ & $28.0 \pm 1.5$ & $25.2 \pm 1.8$ \\
& Change & $-1.7 \pm 1.4$ & $-0.3 \pm 1.0$ & $-0.4 \pm 1.0$ & $-0.6 \pm 0.7$ \\
IMCL:EMCL & Baseline & $0.162 \pm 0.034$ & $0.156 \pm 0.025$ & $0.150 \pm 0.022$ & $0.183 \pm 0.039$ \\
& Endpoint & $0.218 \pm 0.041$ & $0.164 \pm 0.040$ & $0.141 \pm 0.022$ & $0.138 \pm 0.048$ \\
& Change & $0.056 \pm 0.045$ & $0.008 \pm 0.028$ & $-0.001 \pm 0.018$ & $-0.041 \pm 0.040$ \\
\hline
\end{tabular}

Intramyocellular lipid (IMCL) was calculated by magnetic resonance spectral abundance relative to total water content. Extramyocellular lipid (EMCL) was calculated as percent of medial and lateral gastrocnemius cross sectional area. Change is defined as the difference between baseline and endpoint values. Data are presented as mean \pm SEM; $*(p<0.05$, RMANOVA $)$.

Secondary, exploratory analysis using paired sample t-tests revealed a significant within group change in IMCL in DAT only ( $p=0.035$ ) (Figure 3A). The change in IMCL was inversely correlated with change in 25(OH)D in AT and DAT $(r=-0.581, p=0.009)$, but not in sedentary D and CTL counterparts $(r=-0.118, p=0.620)$ (Figure 3B). Within group comparisons did not reveal significant changes in the $[\mathrm{IMCL}] /[\mathrm{EMCL}]$ ratio or EMCL.

\subsection{Fatigue Test with Local Muscle Tissue $\mathrm{BF}, \mathrm{StO}_{2}$ and $\mathrm{VO}_{2}$}

There were no differences between intervention groups in baseline MVC (Table 1). NIRS/DCS measures for both baseline and endpoint were acquired for 37 subjects. Demographic variables (Table 1) did not correlate with hemodynamic NIRS/DCS data at baseline.

Figure A1 illustrates a typical hemodynamic response in $\mathrm{rBF}, \mathrm{rVO}_{2}$, and $\mathrm{StO}_{2}$ in human subjects during fatiguing exercise. Our secondary outcome analysis of NIRS/DCS data during the fatiguing exercise protocol indicated a significant effect of supplementation $\left(p=0.017, \eta^{2}=0.140\right)$ in rBF. Further analysis using ANOVA revealed a main effect $(p=0.049)$, and post hoc analyses indicated a strong trend towards rBF increase from CTL to DAT $(p=0.052)$ (Figure $4 \mathrm{~A})$. At baseline there were no group differences in blood flow during exercise. DAT endpoint rBF $(827 \pm 488$ percent baseline $)$ was higher than CTL ( $385 \pm 148$ percent baseline, $p=0.010)$ and AT (426 \pm 332 percent baseline, $p=0.013)$. There were no significant group by time interactions in $\mathrm{rVO}_{2}$ during exercise; however, secondary analysis by ANOVA revealed DAT was significantly higher at endpoint than CTL $(p=0.007)$, $\operatorname{AT}(p=0.002)$, and $\mathrm{D}(p=0.013)$ (Figure $4 \mathrm{~B})$. No significant differences in $\Delta \mathrm{StO}_{2}$ were found between intervention groups during fatiguing exercise at baseline or at the end of the study. 

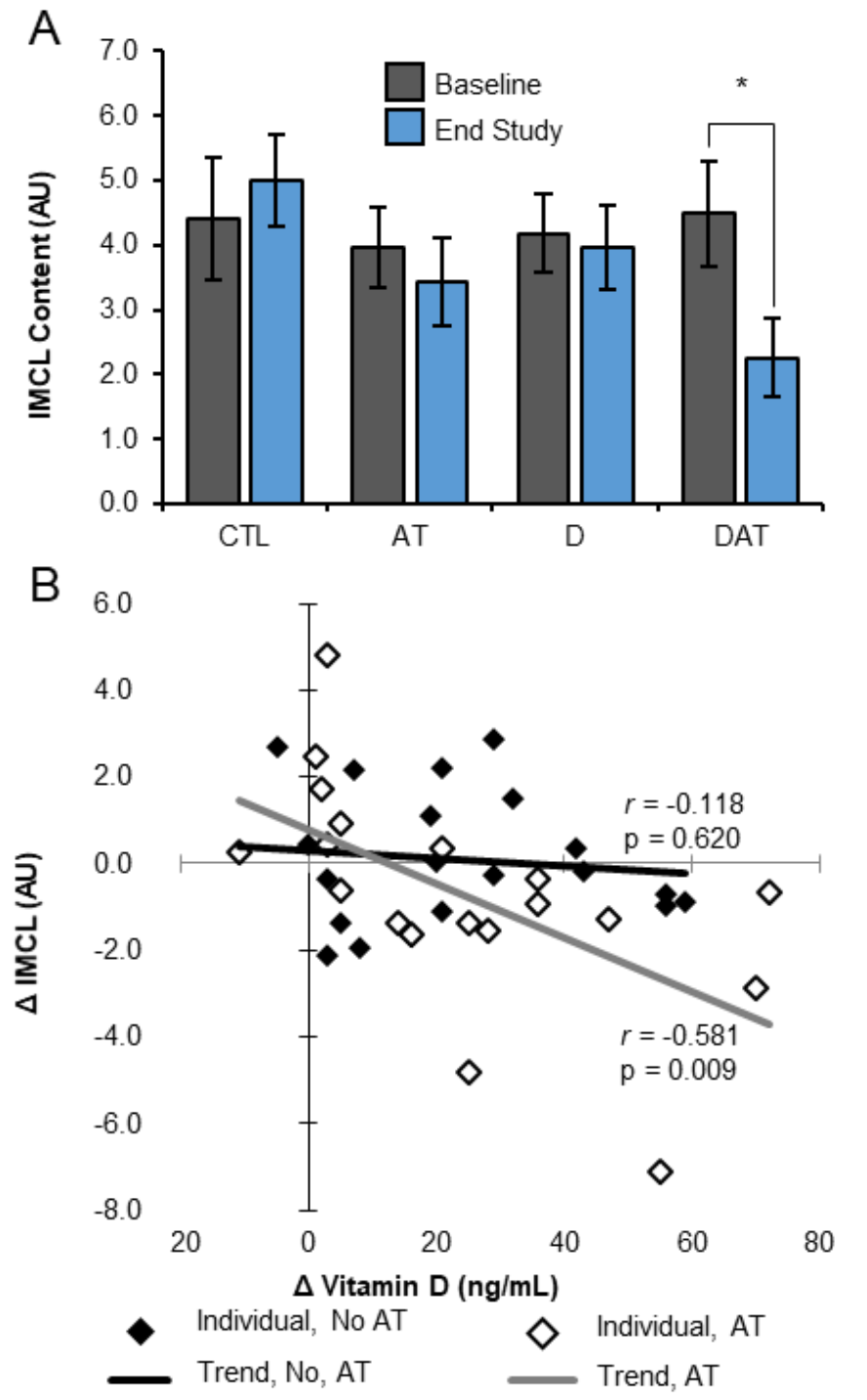

Figure 3. IMCL response to 13 weeks of intervention. (A) DAT decreases IMCL from baseline after 13 weeks. Bars represent mean $\pm \mathrm{SEM}$; $p<0.05$; paired t-test. (B) Change in IMCL content proportional to change in $25(\mathrm{OH}) \mathrm{D}$ concentration from baseline to end point. Serum $25(\mathrm{OH}) \mathrm{D}$, serum 25 -hydroxyvitamin D; AT, aerobic training; AU, arbitrary units; CTL, control; D, vitamin D; DAT, vitamin D + aerobic training; IMCL, intramyocellular lipid.

At endpoint, $\mathrm{rBF}, \mathrm{rVO}_{2}$, and $\mathrm{StO}_{2}$ progressed towards pre-fatigue exercise values during the immediate recovery period ( $\min 1$ to 3 ) following fatiguing exercise. Throughout 15 min of recovery from the fatiguing exercise, there were no main effect differences in $\mathrm{rBF}, \mathrm{rVO}_{2}$, or $\mathrm{StO}_{2}$ by time or by group. We examined shifts in $\Delta \mathrm{StO}_{2}$ from baseline to endpoint for each minute of recovery (min 1-15) and found a significant time by supplement by treadmill interaction effect in $\Delta \mathrm{StO}_{2}$ from 2 min onward $\left(p=0.027, \eta^{2}=0.125\right)$. This difference reached its maximum at $5 \mathrm{~min}$ of recovery and maintained a steady state from 8-15 min (Figure 4C).

While there were no intervention differences by time and/or by group (supplement $p=0.138$; treadmill training $p=0.957$ ) in $\mathrm{rVO}_{2} \mathrm{~T} 50$, paired t-tests showed a significant decrease in $\mathrm{rVO}_{2} \mathrm{~T} 50$ for DAT $(-28.7 \pm 31.3 \mathrm{~s}, p=0.030)$ (Figure $4 \mathrm{D})$. There were no differences among treatments in $\mathrm{StO}_{2} \mathrm{~T} 50$. There were no differences between sexes for any NIRS/DCS variables. 

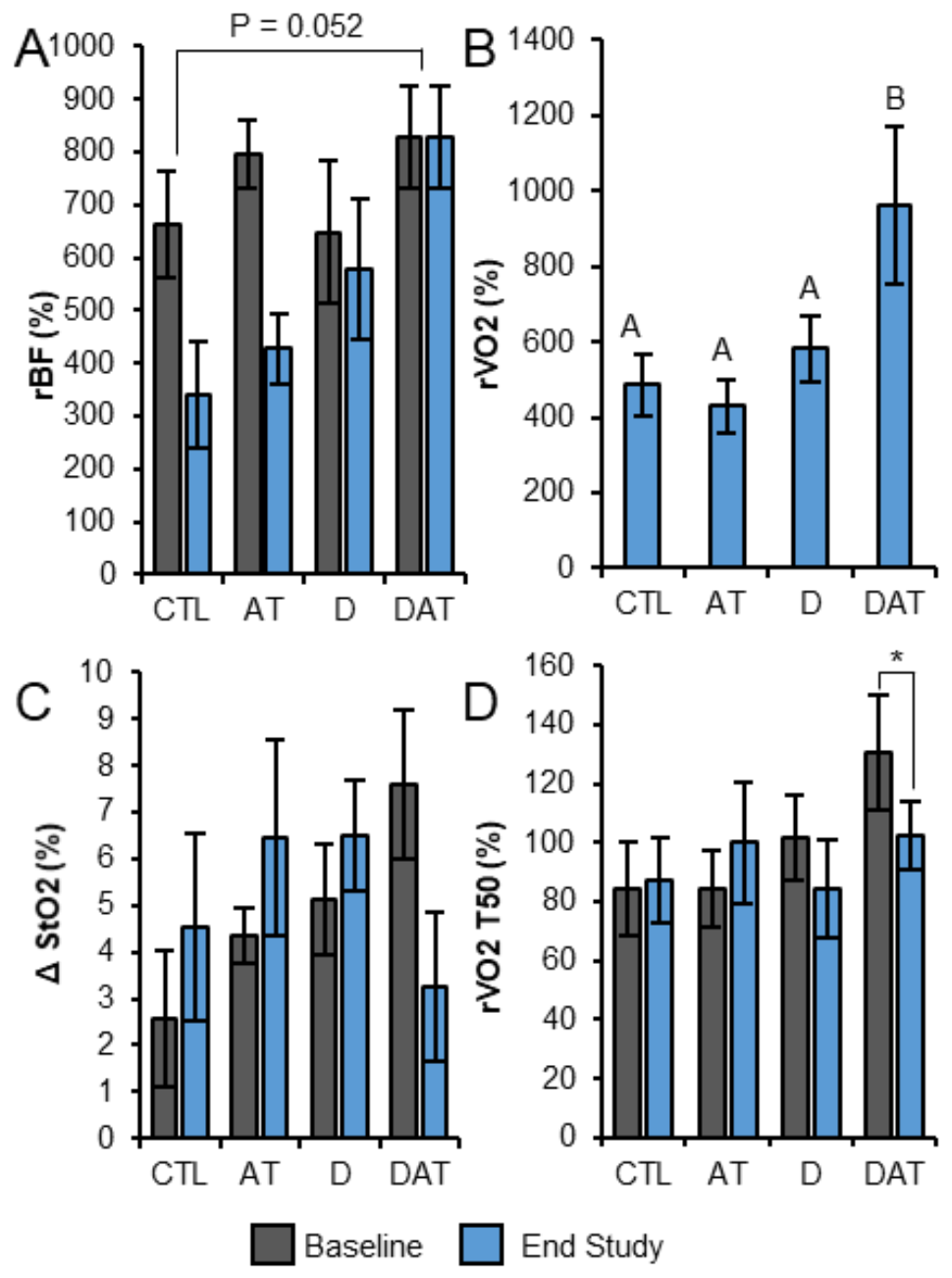

Figure 4. NIRS/DCS measurements in response to 13 weeks of intervention. (A) Relative blood flow during exercise by group. (B) Oxygen consumption by group during exercise at study endpoint. (C) Change in Oxygen saturation by group at study baseline and endpoint at 8 min of recovery after plantar flexion exercise. (D) Recovery half-time of oxygen consumption at study baseline and endpoint. Bars represent mean \pm SEM; labeled means without a common letter differ, $p<0.05$, ANOVA (A) RMANOVA (B); ${ }^{*} p<0.05$, paired $t$-test. AT, aerobic training; CTL, control; D, vitamin D; DAT, vitamin $\mathrm{D}+$ aerobic training; $\mathrm{rBF}$, relative blood flow; $\Delta \mathrm{StO}_{2}$, pre- to post-exercise change in oxygen saturation; $\mathrm{rVO}_{2}$, relative oxygen consumption; $\mathrm{rVO}_{2} \mathrm{~T} 50$, relative oxygen consumption recovery half-time.

\subsection{Other Outcomes}

For D and DAT, mean 25(OH)D concentrations increased over time to $54.1 \pm 10.8$ and $63.7 \pm$ $17.7 \mathrm{ng} / \mathrm{mL}$ at midpoint and endpoint in $\mathrm{D}$ and to $62.0 \pm 14.3$ and $72.1 \pm 16.3 \mathrm{ng} / \mathrm{mL}$ at midpoint and endpoint in DAT, respectively $(p<0.001)$ (Table A1). Change in 25(OH)D was not affected by treadmill training $(p=0.387)$. Serum $25(\mathrm{OH}) \mathrm{D}$ was $31.2 \pm 9.7$ and $32.6 \pm 10.6 \mathrm{ng} / \mathrm{mL}$ at midpoint and endpoint for AT and $29.5 \pm 10.2$ and $31 \pm 10.4 \mathrm{ng} / \mathrm{mL}$ at midpoint and endpoint in CTL. Serum 25(OH)D changes in AT and CTL were also significant by time $(p<0.001)$, and remained significantly lower when compared to $\mathrm{D}(p<0.001)$ and DAT $(p<0.001)$ (time $\mathrm{x}$ group post hoc comparisons). Intact PTH significantly changed over time, and changes in $25(\mathrm{OH}) \mathrm{D}$ concentrations were negatively associated with iPTH $(r=-0.486, p=0.001)$ in the total sample. This appeared to be driven by DAT $(r=-0.725, p=0.027)$. Average subject-reported compliance with vitamin D and placebo supplementation was $93 \%$ and $96 \%$, respectively. 
HOMA-IR, VDBP and iCa were not significantly different between groups at any study time point. Physical activity, total caloric intake, dietary fat and vitamin D intake were not significantly different between intervention groups at baseline or over time (See Table A1).

\section{Discussion}

This was the first clinical trial utilizing novel non-invasive techniques, to examine the combination of vitamin D repletion and AT on muscle lipid and metabolic function in aged muscle. Although our primary analysis examining change in the ratio of intramyocellular lipid (IMCL) to extramyocellular lipid (EMCL) was not significant, our secondary analysis of IMCL, secondary outcomes and exploratory analyses suggested that vitamin D repletion augments aerobic exercise induced IMCL reduction and promotes improvements in muscle metabolic function. Specifically, the combination of aggressive vitamin D repletion and short-term aerobic training (AT) produce the greatest loss of IMCL with concomitant increases in local muscle tissue relative oxygen consumption $\left(\mathrm{rVO}_{2}\right)$. Combination treatment also produced other positive hemodynamic changes including increased relative blood flow $(\mathrm{rBF})$ and $\mathrm{rVO}_{2}$ as well as decreased change in oxygen saturation $\left(\Delta \mathrm{StO}_{2}\right)$ and $\mathrm{rVO}_{2}$ recovery half time (T50). All of these changes are consistent with improved muscle metabolic function and exercise recovery potential.

These findings were observed in a healthy cohort of aged, normal weight, insulin-sensitive, community dwelling subjects and were in partial support of a two-part study hypothesis. First, these findings do not support the first half of our hypothesis, which stated that vitamin D repletion promotes accumulation of IMCL in aged human subjects. Our previous work reported a positive linear relationship between 25-hydroxyvitamin $\mathrm{D}(25(\mathrm{OH}) \mathrm{D})$ and gastrocnemius IMCL in a cross-sectional sample of healthy, aged adults, independent of physical activity and body mass [27]. The D group in the present study did not experience an increase in IMCL content over 13 weeks, despite increasing mean 25(OH)D concentration from 26 to $64 \mathrm{ng} / \mathrm{mL}$. While our current findings do not support our previous work in humans, other work from our group [5,43] shows that vitamin D is involved in lipid droplet filling and gene expression of the adipose related protein, perilipin 2 (PLIN2). We acknowledge that the "quality" of IMCL and factors including lipid species distribution, lipid droplet size, and subcellular localization of lipid droplets may be associated with the capacity to turnover lipid efficiently and may be more important than absolute IMCL content $[5,44-46]$. Nevertheless, one explanation for not seeing a significant IMCL increase in the D group might be that the time spent participating in moderate physical activity as we measured by Actigraph acceleometry was maintained at approximately $1 \mathrm{~h}$ per day throughout the intervention and may have provided significant lipolytic stimulus to maximize lipid turnover and minimize myocellular lipid filling [44].

The second half of our hypothesis - that IMCL is more readily oxidized with the addition of AT-was supported by our current data suggesting that IMCL is more readily used by skeletal muscle with the addition of aerobic training. Data from DAT suggests that IMCL is more readily oxidized in the presence of vitamin D sufficiency. Significant change in IMCL storage and muscle metabolic function $\left(\triangle \mathrm{StO} 2, \mathrm{rVO}_{2}, \mathrm{rVO}_{2} \mathrm{~T} 50\right)$ were only observed after vitamin $\mathrm{D}$ repletion followed by aerobic training with no appreciable changes seen in CTL or subjects who only received aerobic training or vitamin D repletion. This is significant because augmenting IMCL utilization during AT may serve to reduce muscle metabolic dysfunction in aging [44] and help to alleviate progressive loss of strength and function over time.

The loss of IMCL experienced by DAT could be explained by several mechanisms including improved blood flow and improved mitochondrial function. Previous studies suggest that vitamin D coupled with exercise has added positive effects on muscle mitochondrial function [6,7]. In addition, vitamin D receptor (VDR) expression in skeletal muscle was increased by both exercise [20] and vitamin D supplementation and has been associated with muscle regeneration and repair [14,21,22]. These independent effects may suggest an additive effect when exercise is combined with vitamin D repletion. However, the mechanistic link between vitamin D repletion and exercise, muscle lipid 
management, oxidation, and muscle metabolic function in aging, requires further study. Although vitamin D has been linked with increased PLIN2 expression and lipid filling, others have suggested that increased PLIN2 availability on lipid droplets may help increase rates of $\beta$-oxidation [46]. Furthermore, several lipid metabolism pathways involving diacylglycerol acyltransferase (DGAT), peroxisome proliferator-activated receptor $\alpha($ PPAR $\alpha)$ and its target gene carnitine palmitoyltransferase-1 (CPT- 1$)$ have been positively associated with vitamin $\mathrm{D}[21,47]$ but require further investigation in aging.

The lack of change in EMCL was likely due to the short duration of the exercise protocol, lack of significant body weight maintenance, and the large size of the EMCL lipid depot that is less sensitive to change, particularly when body mass remains stable. Although EMCL appears to be inversely related to vitamin D status in other published studies $[13,18]$, short-term aerobic exercise and vitamin $D$ repletion had no effect in this study.

Our key secondary outcome findings were that $\mathrm{rVO}_{2}$ was significantly higher in DAT during the endpoint fatigue protocol and that these results matched the significant loss of IMCL in the same group of subjects. These observations not only show that our 13-week vitamin D repletion + AT protocol promotes the greatest IMCL loss, but also suggests from our non-invasive NIRS/DCS optical findings that IMCL is more readily oxidized with the addition of aerobic exercise following vitamin D repletion.

These findings also align with previous work showing that vitamin D is associated with improvements in oxygen consumption in vitro [7] and skeletal mitochondrial capacity during plantar flexion exercise in clinical setting [6]. Moreover, our group has recently shown that vitamin D can elicit many other distinct effects on myocellular lipid partitioning and lipid packaging potential. This includes changing IMCL subspecies content, partitioning of intramuscular triglycerides between myotubes and myoblasts, and increasing expression of genes involved in lipid droplet packaging and lipolysis [5].

The DAT intervention also had a significant effect on measures of $\mathrm{rBF}, \Delta \mathrm{StO}_{2}$, and recovery half-time oxygen consumption rate $\left(\mathrm{rVO}_{2} \mathrm{~T} 50\right)$. To our surprise, group comparisons of $\mathrm{rBF}$ during fatiguing exercise from study baseline to endpoint indicated a trend towards an increase in $\mathrm{D}$ (compared to CTL and AT) at endpoint, while DAT rBF was significantly higher than CTL despite no group differences in these variables observed during baseline assessment. These observations deserve further attention in future studies given the potential impact of an additive or synergistic effect of a vitamin $\mathrm{D}$ repletion and exercise intervention could have on maintaining muscle metabolic health. A connection between vitamin D and factors related to blood flow such as flow-mediated dilation, vascular endothelial function, endothelial nitric oxide synthase, and erythropoiesis have been documented [48-50], but the specific relationship between exercise and vitamin D on blood flow outcomes is not well described $[48,51]$.

Finally, we examined shifts in $\Delta \mathrm{StO}_{2}$ from study baseline to endpoint for each minute of recovery (min 1-15) to better represent $\mathrm{StO}_{2}$ response to our acute fatigue protocol. DAT was the only group to significantly change oxygen saturation towards full recovery from study baseline to endpoint and DAT $\Delta \mathrm{StO}_{2}$ was significantly reduced from minute 2 through minute 15 . A reduction in $\Delta \mathrm{StO} \mathrm{O}_{2}$ indicates enriched mitochondrial capacity by increasing oxygen extraction to muscles [52]. While it appears that DAT is increased at baseline relative to other groups, this difference was not statistically significant, approaching significance most closely at $2 \mathrm{~min}(p=0.231$, ANOVA). Finally, both vitamin D-supplemented intervention groups (D and DAT) experienced a declining trend decline in their recovery half time $\left(\mathrm{rVO}_{2} \mathrm{~T} 50\right)$, but only DAT experienced a significant decline over time (pre- to post intervention). We interpret a reduction in $\mathrm{DAT}_{\mathrm{rVO}} \mathrm{T} 50$ as a beneficial alteration and potentially an adaptation to support increased muscle oxygen utilization, suggesting improved mitochondrial function $[52,53]$. Together, these changes in hemodynamics and oxygen consumption may be attributed to multiple mechanisms including improved muscle blood flow and oxygen delivery creating a reduction in oxygen debt, [54] improved lipid substrate availability to the mitochondria [32,55], and direct improvements of mitochondrial function $[56,57]$. 
In summary, near-infrared spectroscopy/diffuse correlation spectroscopy (NIRS/DCS) data show increased relative oxygen consumption rate and relative blood flow to active muscles and faster exercise recovery in subjects receiving DAT. This suggests that combining aerobic exercise with vitamin D repletion may help improve muscle metabolic function by influencing local muscle tissue aerobic capacity and post exercise recovery. To our knowledge, these are the first data to show the relationship between vitamin $\mathrm{D}$ repletion, aerobic exercise, and muscle metabolic function with the combined use of inexpensive and non-invasive NIRS/DCS with magnetic resonance spectroscopy (MRS).

The strengths of this study include a randomized design, participant commitment $(\geq 95 \%$ compliance to AT program and $\geq 93 \%$ adherence to supplementation), low study dropout rate, and the blinding of subjects, exercise trainers and study team. Other strengths involved the inclusion of both sexes, monitoring physical activity, dietary energy intake, and knowledge of each subject's insulin sensitivity.

There are also limitations to consider when interpreting these results. While adequately powered when designed, variability in IMCL data was higher than expected and limited our ability to observe significant group differences when analyzing our primary outcome with RMANOVA. Lost data also contributed to study limitations since pre-post IMCL data could only be analyzed in 40 of the 50 subjects recruited. Lost IMCL data were explained by, missing data, uninterpretable MRS spectra caused by low signal:noise, and logistical/scheduling complications. Nine subjects did not have optical spectroscopy data due to either NIRS/DCS or BTE machine instrument failure $(n=7$ [CTL $n=1$; AT $n=2 ; \mathrm{D} n=1$; DAT $n=3$ ]) or unreliable measurements due to noise $(n=2$ [CTL $n=1$; DAT $n=1$ ]). Furthermore, the study sample was comprised of $93 \%$ white subjects, limiting our ability to translate findings to other racial and ethnic groups. Vitamin D binding protein (VDBP) genetic polymorphisms are associated with race and could alter VDBP concentration and binding affinity [58-60]. The functional significance of these genetic polymorphisms is not completely understood, but VDBP can influence vitamin D status and should be considered in future studies. Moreover, our stringent eligibility criteria set forth in an effort to establish and maximize a controlled scientific model of study and establish proof of concept also limits our ability to generalize our results to all aged adults. Finally, we acknowledge that our muscle lipid and hemodynamic findings do not provide direct evidence of IMCL turnover and improved mitochondrial function. However, this work provides novel non-invasive insight to inform future mechanistic studies and future translational work to fully understand the mechanistic underpinnings outlining the benefit of combining exercise and vitamin D treatment on skeletal muscle metabolism.

\section{Conclusions}

In conclusion, the [IMCL]/[EMCL] ratio did not change in our sample of healthy aged subjects. However, these results partially supported our hypothesis that IMCL reduction would be enhanced with the addition of aerobic training following vitamin D repletion, but vitamin D repletion alone did not increase IMCL over 13 weeks. Vitamin D repletion, when combined with AT, may potentiate the metabolic benefits of exercise in aging by reducing IMCL and altering skeletal muscle tissue-level $\mathrm{VO}_{2}$. Future work should test the hypothesis that vitamin $\mathrm{D}$ promotes muscle lipid availability for $\beta$-oxidation in response to exercise, thereby preventing lipotoxicity and improving muscle anabolic sensitivity in populations at risk for sarcopenia and cachexia.

Author Contributions: Conceptualization, D.T.T.; methodology, D.T.T., G.Y.; validation, D.T.T., D.M.S., M.R., M.Z.; formal analysis, D.T.T., D.M.S., H.B.; D.J. investigation, D.M.S., M.R., M.Z., H.B.; resources, D.T.T., G.Y.; data curation, D.M.S., M.R., M.Z., H.A., D.J., H.B.; writing-original draft preparation, D.T.T.; writing-review and editing, D.M.S., M.R., M.Z., H.A., D.J., H.B., G.Y.; visualization, D.M.S.; supervision, D.T.T.; project administration, D.T.T., D.M.S., M.R.; funding acquisition, D.T.T.

Funding: This work was supported by the National Institute on Aging (NIH R21AG046762), along with assistance from UL1TR001998, T32DK007778-16 and 1P20GM121327-01. 
Acknowledgments: The authors would like to thank each research subject for their time spent volunteering for this study. We would like to thank David Powell for his MRI expertise; Doug Long for supporting dynamometer measurements; Alejandro Tezanos and the Applied Statistics Lab for statistical support; and all CCTS staff; Charlotte Peterson for her mentorship. We would also like to thank Bio-tech Pharmacal, Inc. for providing vitamin $\mathrm{D}$ and placebo capsules.

Conflicts of Interest: D.T.T. is a scientific advisor for the Wheat Foods Council, however none of the authors have a conflict of interest to declare related to content of the manuscript. The funders had no role in the design of the study; in the collection, analyses, or interpretation of data; in the writing of the manuscript, or in the decision to publish the results.

\section{Appendix A}
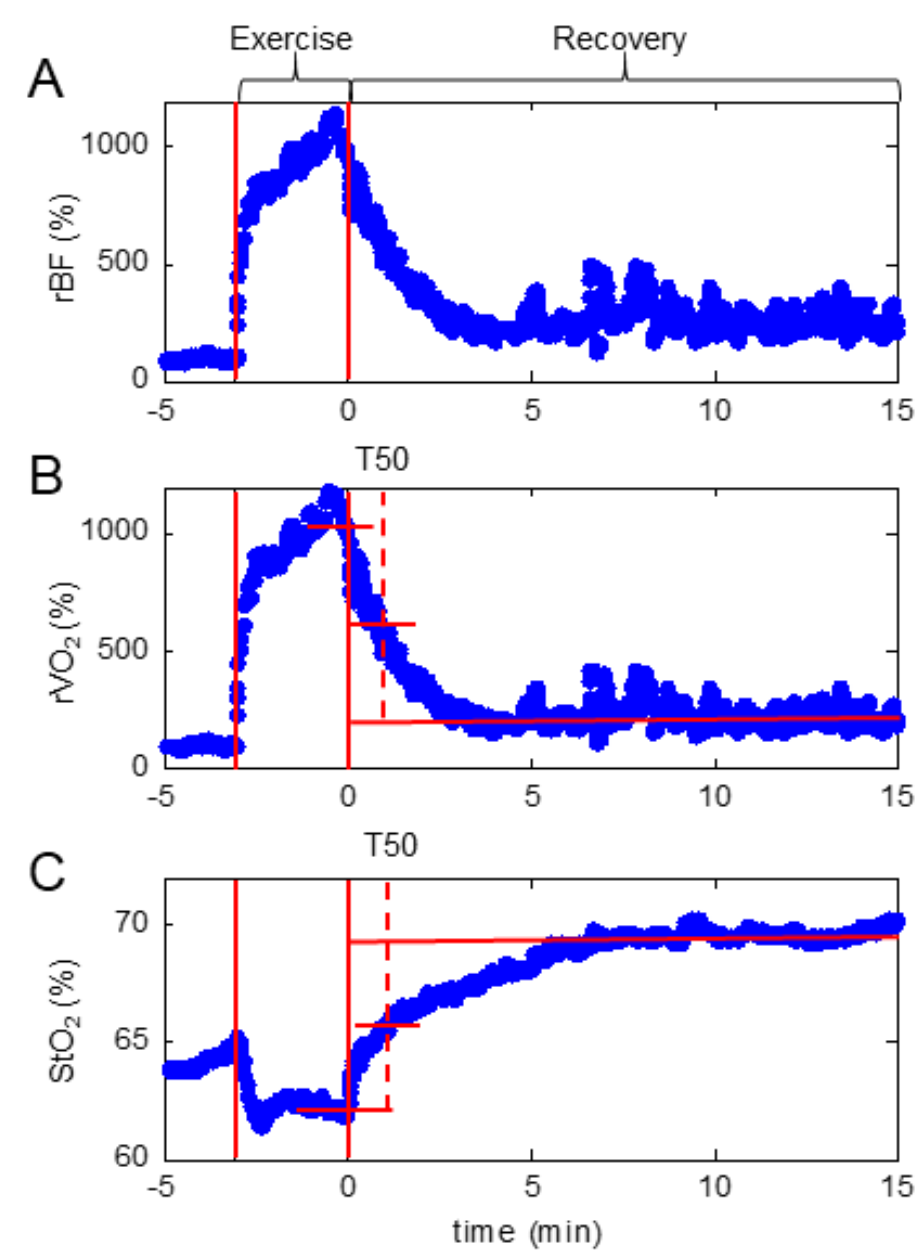

Figure A1. Representative profiles of a typical response seen in subjects when completing the fatiguing exercise. Standard illustrative profile of (A) relative blood flow, (B) relative oxygen consumption rate, and $(C)$ blood oxygen saturation in a subjects throughout fatiguing exercise. Solid vertical lines indicate the beginning and the end of fatiguing exercise. Horizontal lines indicate end of exercise, post-exercise steady-state, and midpoint values. Hashed vertical lines illustrate the recovery half-time (T50) of relative oxygen consumption following fatiguing exercise. $\mathrm{rBF}$, relative blood flow; $\mathrm{rVO}_{2}$, relative oxygen consumption; $\mathrm{StO} 2$, oxygen saturation. 
Table A1. Baseline, midpoint, and endpoint values for blood measurements.

\begin{tabular}{cccccc}
\hline Measurement & Time Point & CTL & AT & D & DAT \\
\hline 25(OH)D, ng/mL & Baseline & $24.8 \pm 2.1$ & $25.2 \pm 1.4$ & $26.6 \pm 1.2$ & $27.1 \pm 1.6$ \\
& Midpoint & $29.5 \pm 3.2^{\mathrm{A}}$ & $31.2 \pm 2.7 * \mathrm{~A}$ & $54.1 \pm 3.0^{* \mathrm{~B}}$ & $62.0 \pm 4.5^{* \mathrm{~B}}$ \\
& End Study & $31.0 \pm 3.3^{* \mathrm{~A}}$ & $32.6 \pm 3.1 * \mathrm{~A}$ & $63.7 \pm 5.0^{* \mathrm{~B}}$ & $72.1 \pm 5.2^{* \mathrm{~B}}$ \\
$\mathrm{VDBP}, \mu \mathrm{g} / \mathrm{mL}$ & Baseline & $110 \pm 5$ & $115 \pm 3$ & $111 \pm 4$ & $115 \pm 5$ \\
& Midpoint & $109 \pm 6$ & $109 \pm 7$ & $109 \pm 5$ & $104 \pm 10$ \\
& End Study & $115 \pm 6$ & $110 \pm 4$ & $110 \pm 4$ & $108 \pm 7$ \\
Ionized Ca, mg/dL & Baseline & $5.01 \pm 0.05$ & $5.09 \pm 0.03$ & $5.09 \pm 0.03$ & $5.04 \pm 0.05$ \\
& Midpoint & $5.00 \pm 0.03$ & $5.12 \pm 0.06$ & $5.09 \pm 0.04$ & $4.97 \pm 0.06$ \\
& End Study & $4.98 \pm 0.02$ & $5.04 \pm 0.04$ & $5.09 \pm 0.04$ & $5.06 \pm 0.07$ \\
Intact PTH, pg/mL & Baseline & $36.8 \pm 3.6 \mathrm{~A}$ & $32.4 \pm 2.6$ & $53.1 \pm 5.5^{\mathrm{B}}$ & $47.6 \pm 5.0 \mathrm{~B}$ \\
& Midpoint & $43.1 \pm 5.6$ & $39.7 \pm 3.8^{*}$ & $39.9 \pm 4.0 *$ & $47.0 \pm 6.3 *$ \\
Insulin, $\mu \mathrm{IU} / \mathrm{mL}$ & End Study & $43.9 \pm 6.9$ & $37.8 \pm 3.4 *$ & $41.7 \pm 3.5 *$ & $41.5 \pm 5.3 *$ \\
& Baseline & $15.3 \pm 3.6$ & $8.0 \pm 1.1$ & $9.22 \pm 1.0$ & $18.5 \pm 6.3$ \\
& Midpoint & $21.5 \pm 9.7$ & $12.2 \pm 2.5$ & $17.9 \pm 3.6$ & $26.9 \pm 14.8$ \\
Glucose, $\mathrm{mg} / \mathrm{dL}$ & End Study & $10.7 \pm 2.9$ & $8.35 \pm 1.2$ & $11.1 \pm 1.3$ & $12.6 \pm 3.0$ \\
& Baseline & $99.0 \pm 4.3$ & $91.7 \pm 4.2$ & $97.2 \pm 2.2$ & $96.3 \pm 1.5$ \\
& Midpoint & - & - & - & - \\
HOMA-IR & End Study & $97.6 \pm 4.0$ & $94.1 \pm 2.1$ & $98.2 \pm 2.2$ & $96.7 \pm 2.8$ \\
& Baseline & $3.93 \pm 1.04$ & $1.78 \pm 0.23$ & $2.23 \pm 0.25$ & $4.34 \pm 1.43$
\end{tabular}

All values presented as mean \pm SEM. ${ }^{*} p<0.05$ vs baseline (paired samples $t$-test); values within a time point not sharing a letter are significantly different $(p<0.05$, ANOVA); - no data collected. AT, aerobic training; CTL, control; $\mathrm{D}$, vitamin D; DAT, vitamin D + aerobic training.

\section{References}

1. Toffanello, E.D.; Perissinotto, E.; Sergi, G.; Zambon, S.; Musacchio, E.; Maggi, S.; Coin, A.; Sartori, L.; Corti, M.C.; Baggio, G.; et al. Vitamin D and physical performance in elderly subjects: The Pro.V.A study. PLoS ONE 2012, 7, e34950. [CrossRef]

2. Verlaan, S.; Maier, A.B.; Bauer, J.M.; Bautmans, I.; Brandt, K.; Donini, L.M.; Maggio, M.; McMurdo, M.E.; Mets, T.; Seal, C.; et al. Sufficient levels of 25-hydroxyvitamin D and protein intake required to increase muscle mass in sarcopenic older adults-The Provide study. Clin. Nutr. 2017, 37, 551-557. [CrossRef]

3. Houston, D.K.; Tooze, J.A.; Neiberg, R.H.; Hausman, D.B.; Johnson, M.A.; Cauley, J.A.; Bauer, D.C.; Cawthon, P.M.; Shea, M.K.; Schwartz, G.G.; et al. 25-hydroxyvitamin D status and change in physical performance and strength in older adults: The health, aging, and body composition study. Am. J. Epidemiol. 2012, 176, 1025-1034. [CrossRef] [PubMed]

4. Sohl, E.; van Schoor, N.M.; de Jongh, R.T.; Visser, M.; Deeg, D.J.; Lips, P. Vitamin D status is associated with functional limitations and functional decline in older individuals. J. Clin. Endocrinol. Metab. 2013, 98, E1483-E1490. [CrossRef] [PubMed]

5. Jefferson, G.E.; Schnell, D.M.; Thomas, D.T.; Bollinger, L.M. Calcitriol concomitantly enhances insulin sensitivity and alters myocellular lipid partitioning in high fat-treated skeletal muscle cells. J. Physiol. Biochem. 2017, 73, 613-621. [CrossRef] [PubMed]

6. Sinha, A.; Hollingsworth, K.G.; Ball, S.; Cheetham, T. Improving the vitamin D status of vitamin D deficient adults is associated with improved mitochondrial oxidative function in skeletal muscle. J. Clin. Endocrinol. Metab. 2013, 98, E509-E513. [CrossRef] [PubMed]

7. Ryan, Z.C.; Craig, T.A.; Folmes, C.D.; Wang, X.; Lanza, I.R.; Schaible, N.S.; Salisbury, J.L.; Nair, K.S.; Terzic, A.; Sieck, G.C.; et al. 1alpha,25-Dihydroxyvitamin D3 regulates mitochondrial oxygen consumption and dynamics in human skeletal muscle cells. J. Biol. Chem. 2016, 291, 1514-1528. [CrossRef] [PubMed]

8. Dutta, D.; Maisnam, I.; Shrivastava, A.; Sinha, A.; Ghosh, S.; Mukhopadhyay, P.; Mukhopadhyay, S.; Chowdhury, S. Serum vitamin-D predicts insulin resistance in individuals with prediabetes. Indian J. Med. Res. 2013, 138, 853-860. 
9. Grant, W.B.; Garland, C.F.; Holick, M.F. Comparisons of estimated economic burdens due to insufficient solar ultraviolet irradiance and vitamin D and excess solar UV irradiance for the United States. Photochem. Photobiol. 2005, 81, 1276-1286. [CrossRef] [PubMed]

10. Bischoff-Ferrari, H.A.; Dawson-Hughes, B.; Orav, E.J.; Staehelin, H.B.; Meyer, O.W.; Theiler, R.; Dick, W.; Willett, W.C.; Egli, A. Monthly High-dose vitamin d treatment for the prevention of functional decline: A randomized clinical trial. JAMA Intern. Med. 2016, 176, 175-183. [CrossRef]

11. Levis, S.; Gomez-Marin, O. Vitamin D and Physical function in sedentary older men. J. Am. Geriatr. Soc. 2017, 65, 323-331. [CrossRef] [PubMed]

12. Domingues-Faria, C.; Boirie, Y.; Walrand, S. Vitamin D and muscle trophicity. Curr. Opin. Clin. Nutr. Metab. Care 2017, 20, 169-174. [CrossRef]

13. Tagliafico, A.S.; Ameri, P.; Bovio, M.; Puntoni, M.; Capaccio, E.; Murialdo, G.; Martinoli, C. Relationship between fatty degeneration of thigh muscles and vitamin D status in the elderly: a preliminary MRI study. AJR Am. J. Roentgenol. 2010, 194, 728-734. [CrossRef] [PubMed]

14. Sato, Y.; Iwamoto, J.; Kanoko, T.; Satoh, K. Low-dose vitamin D prevents muscular atrophy and reduces falls and hip fractures in women after stroke: A randomized controlled trial. Cerebrovasc. Dis. 2005, 20, 187-192, Retracted in Cerebrovasc. Dis. 2017, 44, 240. [CrossRef] [PubMed]

15. Chanet, A.; Salles, J.; Guillet, C.; Giraudet, C.; Berry, A.; Patrac, V.; Domingues-Faria, C.; Tagliaferri, C.; Bouton, K.; Bertrand-Michel, J.; et al. Vitamin D supplementation restores the blunted muscle protein synthesis response in deficient old rats through an impact on ectopic fat deposition. J. Nutr. Biochem. 2017, 46, 30-38. [CrossRef] [PubMed]

16. Liu, E.; Meigs, J.B.; Pittas, A.G.; McKeown, N.M.; Economos, C.D.; Booth, S.L.; Jacques, P.F. Plasma 25-hydroxyvitamin $\mathrm{d}$ is associated with markers of the insulin resistant phenotype in nondiabetic adults. J. Nutr. 2009, 139, 329-334. [CrossRef] [PubMed]

17. Di Rosa, M.; Malaguarnera, M.; Nicoletti, F.; Malaguarnera, L. Vitamin D3: A helpful immuno-modulator. Immunology 2011, 134, 123-139. [CrossRef] [PubMed]

18. Gilsanz, V.; Kremer, A.; Mo, A.O.; Wren, T.A.; Kremer, R. Vitamin D status and its relation to muscle mass and muscle fat in young women. J. Clin. Endocrinol. Metab. 2010, 95, 1595-1601. [CrossRef] [PubMed]

19. Beaudart, C.; Buckinx, F.; Rabenda, V.; Gillain, S.; Cavalier, E.; Slomian, J.; Petermans, J.; Reginster, J.Y.; Bruyere, $\mathrm{O}$. The effects of vitamin $\mathrm{D}$ on skeletal muscle strength, muscle mass, and muscle power: A systematic review and meta-analysis of randomized controlled trials. J. Clin. Endocrinol. Metab. 2014, 99, 4336-4345. [CrossRef]

20. Makanae, Y.; Ogasawara, R.; Sato, K.; Takamura, Y.; Matsutani, K.; Kido, K.; Shiozawa, N.; Nakazato, K.; Fujita, S. Acute bout of resistance exercise increases vitamin D receptor protein expression in rat skeletal muscle. Exp. Physiol. 2015, 100, 1168-1176. [CrossRef] [PubMed]

21. Yin, Y.; Yu, Z.; Xia, M.; Luo, X.; Lu, X.; Ling, W. Vitamin D attenuates high fat diet-induced hepatic steatosis in rats by modulating lipid metabolism. Eur. J. Clin. Investig. 2012, 42, 1189-1196. [CrossRef] [PubMed]

22. Srikuea, R.; Zhang, X.; Park-Sarge, O.K.; Esser, K.A. VDR and CYP27B1 are expressed in C2C12 cells and regenerating skeletal muscle: Potential role in suppression of myoblast proliferation. Am. J. Physiol. Cell Physiol. 2012, 303, C396-C405. [CrossRef] [PubMed]

23. Marcotorchino, J.; Tourniaire, F.; Astier, J.; Karkeni, E.; Canault, M.; Amiot, M.J.; Bendahan, D.; Bernard, M.; Martin, J.C.; Giannesini, B.; et al. Vitamin D protects against diet-induced obesity by enhancing fatty acid oxidation. J. Nutr. Biochem. 2014, 25, 1077-1083. [CrossRef] [PubMed]

24. Agergaard, J.; Trostrup, J.; Uth, J.; Iversen, J.V.; Boesen, A.; Andersen, J.L.; Schjerling, P.; Langberg, H. Does vitamin-D intake during resistance training improve the skeletal muscle hypertrophic and strength response in young and elderly men?-A randomized controlled trial. Nutr. Metab. 2015, 12, 32. [CrossRef] [PubMed]

25. Volpi, E.; Nazemi, R.; Fujita, S. Muscle tissue changes with aging. Curr. Opin. Clin. Nutr. Metab. Care 2004, 7, 405-410. [CrossRef]

26. Kim, J.E.; Dunville, K.; Li, J.; Cheng, J.X.; Conley, T.B.; Couture, C.S.; Campbell, W.W. Intermuscular adipose tissue content and intramyocellular lipid fatty acid saturation are associated with glucose homeostasis in middle-aged and older adults. Endocrinol. Metab. 2017, 32, 257-264. [CrossRef] [PubMed]

27. Redzic, M.; Powell, D.K.; Thomas, D.T. Vitamin D status is related to intramyocellular lipid in older adults. Endocrine 2014, 47, 854-861. [CrossRef] 
28. Sakurai, Y.; Tamura, Y.; Takeno, K.; Kumashiro, N.; Sato, F.; Kakehi, S.; Ikeda, S.; Ogura, Y.; Saga, N.; Naito, H.; et al. Determinants of intramyocellular lipid accumulation after dietary fat loading in non-obese men. J. Diabetes Investig. 2011, 2, 310-317. [CrossRef]

29. Shaw, C.S.; Clark, J.; Wagenmakers, A.J. The effect of exercise and nutrition on intramuscular fat metabolism and insulin sensitivity. Annu. Rev. Nutr. 2010, 30,13-34. [CrossRef]

30. Takiishi, T.; Gysemans, C.; Bouillon, R.; Mathieu, C. Vitamin D and diabetes. Endocrinol. Metab. Clin. N. Am. 2010, 39, 419-446. [CrossRef]

31. Cree, M.G.; Newcomer, B.R.; Katsanos, C.S.; Sheffield-Moore, M.; Chinkes, D.; Aarsland, A.; Urban, R.; Wolfe, R.R. Intramuscular and liver triglycerides are increased in the elderly. J. Clin. Endocrinol. Metab. 2004, 89, 3864-3871. [CrossRef]

32. Dube, J.J.; Amati, F.; Stefanovic-Racic, M.; Toledo, F.G.; Sauers, S.E.; Goodpaster, B.H. Exercise-induced alterations in intramyocellular lipids and insulin resistance: The athlete's paradox revisited. Am. J. Physiol. Endocrinol. Metab. 2008, 294, E882-E888. [CrossRef]

33. Pruchnic, R.; Katsiaras, A.; He, J.; Kelley, D.E.; Winters, C.; Goodpaster, B.H. Exercise training increases intramyocellular lipid and oxidative capacity in older adults. Am. J. Physiol. Endocrinol. Metab. 2004, 287, E857-E862. [CrossRef] [PubMed]

34. Haus, J.M.; Solomon, T.P.; Lu, L.; Jesberger, J.A.; Barkoukis, H.; Flask, C.A.; Kirwan, J.P. Intramyocellular lipid content and insulin sensitivity are increased following a short-term low-glycemic index diet and exercise intervention. Am. J. Physiol. Endocrinol. Metab. 2011, 301, E511-E516. [CrossRef] [PubMed]

35. Metcalf, B.S.; Curnow, J.S.; Evans, C.; Voss, L.D.; Wilkin, T.J. Technical reliability of the CSA activity monitor: The Earlybird study. Med. Sci. Sports Exerc. 2002, 34, 1533-1537. [CrossRef] [PubMed]

36. Warren, W.T.; Robert, W. Fully proportional actigraphy: A new instrument. Behav. Res. Meth. Instrum. Comput. 1996, 28, 392-403.

37. American College of Sports Medicine; Riebe, D.; Ehrman, J.K.; Liguori, G.; Magal, M. ACSM's Guidelines for Exercise Testing and Prescription, 10th ed.; Wolters, K., Ed.; Lippincott Williams \& Wilkins: Pennsylvania, PA, USA, 2018; p. 472.

38. Holick, M.F.; Binkley, N.C.; Bischoff-Ferrari, H.A.; Gordon, C.M.; Hanley, D.A.; Heaney, R.P.; Murad, M.H.; Weaver, C.M.; Endocrine, S. Evaluation, treatment, and prevention of vitamin D deficiency: An endocrine society clinical practice guideline. J. Clin. Endocrinol. Metab. 2011, 96, 1911-1930. [CrossRef]

39. Hollis, B.W. Circulating 25-hydroxyvitamin D levels indicative of vitamin D sufficiency: implications for establishing a new effective dietary intake recommendation for vitamin D. J. Nutr. 2005, 135, 317-322. [CrossRef]

40. Gurley, K.; Shang, Y.; Yu, G. Noninvasive optical quantification of absolute blood flow, blood oxygenation, and oxygen consumption rate in exercising skeletal muscle. J. Biomed. Opt. 2012, 17, 075010. [CrossRef]

41. Henry, B.; Zhao, M.; Shang, Y.; Uhl, T.; Thomas, D.T.; Xenos, E.S.; Saha, S.P.; Yu, G. Hybrid diffuse optical techniques for continuous hemodynamic measurement in gastrocnemius during plantar flexion exercise. J. Biomed. Opt. 2015, 20, 125006. [CrossRef]

42. Shang, Y.; Symons, T.B.; Durduran, T.; Yodh, A.G.; Yu, G. Effects of muscle fiber motion on diffuse correlation spectroscopy blood flow measurements during exercise. Biomed. Opt. Express 2010, 1, 500-511. [CrossRef] [PubMed]

43. Schnell, D.M.; Walton, R.G.; Vekaria, H.J.; Sullivan, P.G.; Bollinger, L.M.; Peterson, C.A.; Thomas, D.T. Vitamin D produces a perilipin 2-dependent increase in mitochondrial function in C2C12 myotubes. J. Nutr. Biochem. 2019, 65, 83-92. [CrossRef] [PubMed]

44. Funai, K.; Semenkovich, C.F. Skeletal muscle lipid flux: Running water carries no poison. Am. J. Physiol. Endocrinol. Metab. 2011, 301, E245-E251. [CrossRef] [PubMed]

45. Bosma, M.; Hesselink, M.K.C.; Sparks, L.M.; Timmers, S.; Ferraz, M.J.; Mattijssen, F.; van Beurden, D.; Schaart, G.; de Baets, M.H.; Verheyen, F.K.; et al. Perilipin 2 improves insulin sensitivity in skeletal muscle despite elevated intramuscular lipid levels. Diabetes 2012, 61, 2679-2690. [CrossRef]

46. Shepherd, S.O.; Cocks, M.; Tipton, K.D.; Ranasinghe, A.M.; Barker, T.A.; Burniston, J.G.; Wagenmakers, A.J.; Shaw, C.S. Preferential utilization of perilipin 2-associated intramuscular triglycerides during $1 \mathrm{~h}$ of moderate-intensity endurance-type exercise. Exp. Physiol. 2012, 97, 970-980. [CrossRef]

47. Lefebvre, P.; Chinetti, G.; Fruchart, J.C.; Staels, B. Sorting out the roles of PPAR alpha in energy metabolism and vascular homeostasis. J. Clin. Investig. 2006, 116, 571-580. [CrossRef] 
48. Koundourakis, N.E.; Androulakis, N.E.; Malliaraki, N.; Margioris, A.N. Vitamin D and exercise performance in professional soccer players. PLoS ONE 2014, 9, e101659. [CrossRef]

49. Jablonski, K.L.; Chonchol, M.; Pierce, G.L.; Walker, A.E.; Seals, D.R. 25-Hydroxyvitamin D deficiency is associated with inflammation-linked vascular endothelial dysfunction in middle-aged and older adults. Hypertension 2011, 57, 63-69. [CrossRef]

50. Andrukhova, O.; Slavic, S.; Zeitz, U.; Riesen, S.C.; Heppelmann, M.S.; Ambrisko, T.D.; Markovic, M.; Kuebler, W.M.; Erben, R.G. Vitamin D is a regulator of endothelial nitric oxide synthase and arterial stiffness in mice. Mol. Endocrinol. 2014, 28, 53-64. [CrossRef]

51. Parker, B.; Capizzi, J.; Augeri, A.; Grimaldi, A.; Proctor, D.; Thompson, P. Sex-specific effect of aging on submaximal leg exercise hemodynamics in middle-aged and older adults. Eur. J. Appl. Physiol. 2011, 111, 1369-1379. [CrossRef]

52. Shang, Y.; Gurley, K.; Symons, B.; Long, D.; Srikuea, R.; Crofford, L.J.; Peterson, C.A.; Yu, G. Noninvasive optical characterization of muscle blood flow, oxygenation, and metabolism in women with fibromyalgia. Arthritis Res. Ther. 2012, 14, R236. [CrossRef] [PubMed]

53. Baty, F.; Ritz, C.; Jensen, S.M.; Kern, L.; Tamm, M.; Brutsche, M.H. Multimodel inference applied to oxygen recovery kinetics after 6-min walk tests in patients with chronic obstructive pulmonary disease. PLoS ONE 2017, 12, e0187548. [CrossRef]

54. McMahon, S.; Wenger, H.A. The relationship between aerobic fitness and both power output and subsequent recovery during maximal intermittent exercise. J. Sci. Med. Sport 1998, 1, 219-227. [CrossRef]

55. Zacharewicz, E.; Hesselink, M.K.C.; Schrauwen, P. Exercise counteracts lipotoxicity by improving lipid turnover and lipid droplet quality. J. Intern. Med. 2018. [CrossRef] [PubMed]

56. Phielix, E.; Meex, R.; Moonen-Kornips, E.; Hesselink, M.K.; Schrauwen, P. Exercise training increases mitochondrial content and ex vivo mitochondrial function similarly in patients with type 2 diabetes and in control individuals. Diabetologia 2010, 53, 1714-1721. [CrossRef]

57. Menshikova, E.V.; Ritov, V.B.; Fairfull, L.; Ferrell, R.E.; Kelley, D.E.; Goodpaster, B.H. Effects of exercise on mitochondrial content and function in aging human skeletal muscle. J. Gerontol. A Biol. Sci. Med. Sci. 2006, 61, 534-540. [CrossRef]

58. Yousefzadeh, P.; Shapses, S.A.; Wang, X. Vitamin D Binding protein impact on 25-hydroxyvitamin D levels under different physiologic and pathologic conditions. Int. J. Endocrinol. 2014, 2014, 981581. [CrossRef]

59. Powe, C.E.; Evans, M.K.; Wenger, J.; Zonderman, A.B.; Berg, A.H.; Nalls, M.; Tamez, H.; Zhang, D.; Bhan, I.; Karumanchi, S.A.; et al. Vitamin D-binding protein and vitamin D status of black Americans and white Americans. N. Engl. J. Med. 2013, 369, 1991-2000. [CrossRef]

60. Hoofnagle, A.N.; Eckfeldt, J.H.; Lutsey, P.L. Vitamin D-binding protein concentrations quantified by mass spectrometry. N. Engl. J. Med. 2015, 373, 1480-1482. [CrossRef] 